\title{
TRANSNASAL ENDOSCOPIC PRELACRIMAL RECESS APPROACH IN A SURGICAL TREATMENT OF ANTROCHOANAL POLYP
}

\author{
By
}

\author{
Ahmed M. Khalefa, Ahmed S. Gad, Abd El-Rahman Sheta Abd El- \\ Rahman \\ Otorhinolaryngology, Faculty of Medicine, Al-Azhar University, Cairo
}

E-Mail: boody_sheta2015@yahoo.com

\begin{abstract}
Background: Antrochoanal polyps (ACPs) are benign polypoid lesions arising from the mucosa of the maxillary sinus, through the maxillary sinus ostium with extension into the choana. They represent approximately $4-6 \%$ of all nasal polyps in the general population. Antrochoanal polyps are almost always unilateral, although there are few cases of bilateral ACPs in the literature.

Objective: To assess the effectiveness of endoscopic transnasal prelacrimal recess approach (ETPRA) in preventing the recurrence of antrochoanal polyps and evaluate the outcomes and possible complications of prelacrimal recess approach for treatment of antrochoanal polyps.

Patient and Methods: forty patients with antrochoanal polyp underwent surgery with a transnasal endoscopic prelacrimal recess approach. The approach was evaluated for the ability to visualise the origin of the polyp in the maxillary cavity, complications and recurrence of the polyp.

Results: Transnasal prelacrimal recess approach was successful in $80 \%$ of the patients (32/40), $80 \%$ of patients (32/40) did not encounter epiphora postoperatively, $85 \%$ of them (34/40) had no epistaxis, $90 \%$ of them (36/40) had no cheek edema. None of them had nasal obstruction, nasal stenosis or adhesions, All of them had the flap healed, and all of them had the inferior turbinate preserved. During the follow-up period (1 year) no recurrence had developed.
\end{abstract}

Conclusion: Prelacrimal recess approach is a safe procedure which allows for complete removal of the antral part of the antrochoanal polyps to prevent recurrence without major complications.

Keywords: Prelacrimal recess approach, antrochoanal polyp.

\section{INTRODUCTION}

Antrochoanal polyps (ACPs) are benign polypoid lesions arising from the maxillary antrum and they extend into the choana. ACPs usually have two components and these are the cystic and solid polypoid parts (Balikci, 2013).

They occur more commonly in children and young adults, and they are almost always unilateral. The etiopathogenesis of ACPs is not clear.
Nasal obstruction and nasal discharge are the most common presenting symptoms. Nasal endoscopy and CT are the main diagnostic techniques (Yaman et al., 2010).

The treatment in ACPs is essentially surgical, simple polypectomy and a Caldwell Luc procedure were the previously preferred methods for surgically treating ACPs. In recent years, functional endoscopic sinus surgery 
(FESS) became the more preferred surgical technique (Rosenthal et al., 2016).

Endoscopic sinus surgery with middle meatal antrostomy has become the most popular approach in ACP treatment. This approach, a minimal invasive and effective method, provides complete removal with negligible complications (Eladl and Elmorsy, 2011).

However, endoscopic sinus surgery alone may not be sufficient because of the inaccessibility to the stalk of the polyp in the maxillary sinus wall and narrow intranasal structures (nasal cavity, ostia, and middle meatus). The recurrence rate with simple polypectomy is high. To prevent recurrence of ACP, the maxillary stalk of the polyp should be removed (Freund et al., 2012).

The transnasal prelacrimal recess approach is a novel surgical technique for the treatment of sinonasal tumors. This approach provides a wide and clear surgical view and allows easy access to the maxillary antrum to resect tumor and adjacent structures together, and therefore minimizes recurrence (He et al., 2014).

Prelacrimal recess is a concavity in the medial, anterosuperior part of the maxillary sinus. It is located in front of the eminence of the lacrimal passages on the medial wall of maxillary sinus (Al Ayadi, Mohammed A., et al., 2015).

Transnasal prelacrimal recess approach allowed complete resection of the antral part of the antrochoanal polyp tissue without traditional open surgical procedures (Comoglu et al., 2016).

\section{PATIENTS AND METHODS}

This was a prospective study conducted on forty patients presented to Al-Azhar University Hospitals (AlHussien \& Sayed Galal) in outpatient clinic was diagnosed to have antrochoanal polyp.

\section{was diagnosed to have antrochoanal polyp.}

\section{Inclusion criteria:}

1. Patients aged above 6 year old.

2. Primary \& recurrent antrochoanal polyp.

\section{Exclusion criteria:}

1. Patients aged below 6 years.

2. Patients with uncontrolled systemic diseases or coagulopathy.

3. Patients with sinonasal polyposis.

Preoperatively, all patients were subjected to:

1. Full history taking.

2. Complete otorhinolaryngeal examination including nasal endoscopy.

3. Computed tomography scan for nose and paranasal sinuses coronal and axial views.

4. Routine laboratory investigations including blood sugar, complete blood count, coagulation profile, renal and liver function tests.

\section{Postoperative care and follow up:}

Nasal pack is removed after one day. Postoperatively all patients received oral antibiotics for 7 days, alkaline nasal wash for at least one month. All patients were subjected to Complete Otorhinolaryngeal 
examination after 1 week of surgery and then every week for one month then every month for one year. Postoperative follow up is done for one year including nasal endoscopy and CT scan.

\section{Statistical analysis:}

Recorded data were analyzed using the statistical package for social sciences, version 20.0 (SPSS Inc., Chicago, Illinois, USA). Quantitative data were expressed as mean \pm standard deviation (SD) and range. Qualitative data were expressed as frequency and percentage. The following tests were done:

-Independent-samples t-test of significance was used when comparing between two means.

-Paired sample t-test of significance was used when comparing between related samples.

- Chi-square (x2) test of significance was used in order to compare proportions between qualitative parameters.

\section{RESULTS}

This study included 40 patients with antrochoanal polyps presented to AlAzhar university Hospitals outpatient clinic, to evaluate the benefits and possible complications of prelacrimal recess approach for treatment of antrochoanal polyps.
Patients' ages ranged from 6 years to 55 years with a mean age \pm SD was $24.1 \pm 10.4$ years.

No statistically significant difference according to demographic data (Table 1).

Table (1): Patients' characteristics

\begin{tabular}{|l|c|c|}
\hline Characters & Frequency (40) & Percent (100\%) \\
\hline $\begin{array}{l}\text { Gender } \\
\text { male }\end{array}$ & 14 & $35 \%$ \\
female & 26 & $65 \%$ \\
\hline Affected side & & \\
$\quad$ left & 28 & $70 \%$ \\
right & 12 & $30 \%$ \\
\hline $\begin{array}{l}\text { Associated pathology } \\
\text { deviated septum to the same side }\end{array}$ & 8 & $20 \%$ \\
\hline
\end{tabular}

No statistically significant difference according to clinical presentation (Table 2).

Table (2): Clinical presentation of patients under the study

\begin{tabular}{|l|c|c|}
\hline Symptoms & Frequency (40) & Percent (100\%) \\
\hline Nasal obstruction( unilateral) & 40 & $100 \%$ \\
\hline Rhinorrhea (unilateral) & 40 & $100 \%$ \\
\hline Snoring & 32 & $80 \%$ \\
\hline Headache & 28 & $70 \%$ \\
\hline
\end{tabular}

The duration of operations ranged from 40 minutes to 60 minutes.

The mean time $\pm \mathrm{SD}=50.5 \pm 6.4$. 
Middle meatal antrostomy succeeded to remove the polyp completely in $20 \%$ of cases and in $80 \%$ of cases, residual tissue of the polyp was found inside the maxillary cavity and the prelacrimal recess approach succeeded to remove it completely (Table 3).

Table (3): Findings during the operation of patients under the study

\begin{tabular}{|l|c|c|}
\hline Signs & Frequency (40) & Percent (100\%) \\
\hline $\begin{array}{l}\text { Site of protrusion of the polyp } \\
\text { natural ostium } \\
\text { accessory ostia }\end{array}$ & 30 & $75 \%$ \\
\hline Origin in the maxillary & 10 & $25 \%$ \\
sinus Posterior wall & 20 & $50 \%$ \\
Inferior wall & 12 & $30 \%$ \\
Lateral wall & 8 & $20 \%$ \\
\hline
\end{tabular}

During the early postoperative follow up period, 8 patients $(20 \%)$ had temporary epiphora that resolved within 10 days without treatment and all patients had crustations which all fall after one month with the use of alkaline nasal wash.

No patient developed recurrence during the follow up period which was for one year (Table 4).

Table (4): Post-operative complications

\begin{tabular}{|l|c|c|}
\hline Items & Frequency (40) & Percent (100\%) \\
\hline $\begin{array}{l}\text { Epiphora } \\
\text { temporary) }\end{array}$ & 8 & $20 \%$ \\
\hline Nasal obstruction & 0 & $0 \%$ \\
\hline Epistaxis & 6 & $15 \%$ \\
\hline cheek edema(temporary) & 4 & $10 \%$ \\
\hline $\begin{array}{l}\text { Healing of the flap } \\
\text { Healed }\end{array}$ & 40 & $100 \%$ \\
\hline Nasal stenosis & 0 & $0 \%$ \\
\hline Adhesion & 0 & $0 \%$ \\
\hline
\end{tabular}

\section{DISCUSSION}

The treatment of antrochoanal polyps (ACPs) is essentially surgical. The Caldwell-Luc operation has been practiced for nearly 100 years. The Caldwell-Luc approach offers good exposure and ensures complete removal of the polyp and the associated antral mucosa. However, the Caldwell-Luc procedure may have possible side effects including cheek anaesthesia, cheek swelling and carries risks to the developing teeth in children (ElSharkawy, 2013).
Endoscopic sinus surgery with middle meatal antrostomy has become the most popular approach in ACP treatment. This approach, a minimal invasive and effective method and provides complete removal with negligible complications (Eladl and Elmorsy et al., 2011).

However, endoscopic sinus surgery alone may not be sufficient because of the inaccessibility to the stalk of the polyp in the maxillary sinus wall and narrow intranasal structures (as nasal cavity, ostia, and middle meatus). To prevent recurrence of $\mathrm{ACP}$, the maxillary stalk of 


\section{TRANSNASAL ENDOSCOPIC PRELACRIMAL RECESS APPROACH IN...}

the polyp should be removed (Freund et al., 2012).

Some authors used endoscopic sinus surgery combined to other approaches as trasnscanine and mini Caldwell- Luc to prevent recurrence as these combined approaches allow better visualization of the maxillary sinus and accordingly complete removal of the antral part of the polyp. However, this combined approach cannot avoid the previously mentioned complications of the traditional open techniques (Atighechi et al., 2010).

The prelacrimal recess approach is a surgical technique for the treatment of sinonasal tumors. This approach provides a wide and clear surgical view and allows easy access to the maxillary antrum to resect tumor and adjacent structures together,and therefore minimizes recurrence (Zhou et al., 2013).

This study was developed to evaluate the outcomes and possible complications of prelacrimal recess approach for treatment of primary antrochoanal polyps.

In our study middle meatal antrostomy succeeded to completely remove the antral portion of the polyps from $20 \%$ of cases. In $80 \%$ of cases residual part of the polyp was found in the maxillary sinus after middle meatal antrostomy. The prelacrimal recess approach allowed good visualization of the maxillary sinus with complete removal of the antral part of these polyps. $50 \%$ of the polyps were found originating from the posterior wall of the maxillary sinus, $30 \%$ from inferior wall and $20 \%$ from lateral wall.

This agrees with the results of the study of Comoglu and Co-workers (2016) where the transnasal prelacrimal recess approach was successful in $83 \%$ of the patients and $17 \%$ of the polyps were excised using the middle meatal antrosyomy. The antral part of the antrochoanal polyps was found to be located anteromedially in $16.6 \%, 33.3 \%$ in anterolateral corner, $25 \%$ in lateral, and $16.6 \%$ in the posterior wall of the maxillary sinus of all polyps.

In our study only $20 \%$ of cases had temporary epiphora, $15 \%$ had epistaxis and $10 \%$ had cheek edema. None of them had nasal obstruction, nasal stenosis or adhesions. The flap healed completely in all patients and the inferior turbinate was preserved.

Comoglu and Co-workers (2016) revealed no cases encountered epiphora postoperatively. $25 \%$ of patients had synechiae formation between the lateral nasal wall and septum just superior to the inferior turbinate. One of them needed surgical treatment under local anaesthesia. They did not found any other complication with the prelacrimal approach.

Zhou and Co-helpers (2013) found neither epiphora nor other postoperative complications. The mucosa healed well and inferior turbinate was preserved in all patients.

In our study, the prelacrimal recess approach was successful in complete removal of the antral part of the polyp without traditional open surgical techniques. No recurrence occurred to any of the patients during the follow up period which was for one year.

Zhou and Co-helpers (2013) used the prelacrimal recess approach for their treatment,and no recurrence was seen in 
$95 \%$ of cases. The follow-up ranged from 7 to 60 months.

Comoglu and Co-workers (2016) on 12 patients with recurrent antrochoanal polyps, they found no recurrence during the follow up period that ranged from 8 to 21 months.

The limitations of our study were that: children were excluded from this study, although the incidence and recurrence higher in children. This was because safety of this novel approach and its effect on the maxillary sinus growth is not well researched.

Small sample size and short follow up periods were also limitations of this study. Better assessment of the approach safety and efficacy to prevent recurrence could be achieved by more studies with larger sample size and longer follow up periods.

Recurrent cases were excluded from this study which is better to be included in future studies.

Finally, the prelacrimal recess is not a constant landmark as it may be absent in some people so these approach cannot be generalized in all cases with antrochoanal polyps.

\section{CONCLUSION}

Endoscopic prelacrimal recess approach provides a better view of the antrum to remove antrochoanal polyp completely.

\section{REFERENCES}

1. Atighechi S., Baradaranfar M., Karimi G. and Jafari R. (2010): Antrochoanal polyp: a comparative study of endoscopic endonasal surgery alone and endoscopic endonasal plus mini- Caldwell technique. Eur Arch Otorhinolaryngol, 266(8): 1245-1248.
2. Al Ayadi, Mohammed A. (2015): "The role of intranasal prelacrimal recess approach in complete removal of anterior maxillary sinus lesions." The Egyptian Journal of Otolaryngology, 31.4213.

3. Balikci, H. (2013): Antrochoanal polyposis: analysis of 34 cases. European Archives of Oto-Rhino-Laryngology, 270(5): 1651-1654.

4. Comoglu S., Celik M., Enver N., Sen C., Polat B. and Deger K. (2016): Transnasal prelacrimal recess approach for recurrent antrachoanal polyp. Journal of Craniofacial Surgery, 27(4): 1025-1027.

5. Eladl H. and Elmorsy S. (2011): Endoscopic surgery in pediatric recurrent antrochoanal polyp, rule of wide ostium. Int J Pediatr Otorhinolaryngoly, 75:1372-1375.

6. El-Sharkawy, A. A. (2013): "Endoscopic management of paediatric antrochoanal polyp: our experience. Acta Otorhinolaryngologica Italica, 33(2): 107-113.

7. Freund, W. (2012): Rhinology and Skull Base Surgery. Year Book of OtolaryngologyHead and Neck Surgery 2012-E-Book: 185.

8. He S., Bakst R., Guo T. and Sun J. (2014): A combination of modified transnasal endoscopic maxillectomy via transnasal prelacrimal recess approach with or without radiotherapy for selected sinonasal malignancies. Eur Arch Otorhinolaryngoly, 272:2933-2938.

9. Rosenthal, Laura H. Swibel, Monica O. Patadia, and James A. Stankiewicz, (2016): Otolaryngology: A Color Handbook. CRC Press.

10. Yaman H., Yilmaz S., Karali E., Guclu E. and Ozturk O. (2010): Evaluation and management of antrochoanal polyps. Clinical and Experimental Otorhinolaryngology, 3(2) : 110-118.

11. Zhou B, Han D. and Cui S. (2013): Intranasal endoscopic prelacrimal recess approach to maxillary sinus. Chin Med J, 126: $1276-1280$. 


\section{إستخدام مأتى ما قبل التجويف الدمعي في العلاج الجراحي

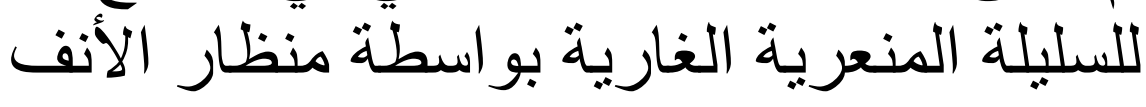

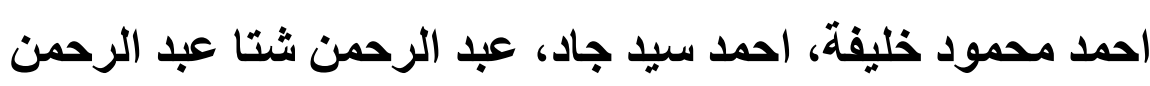

\section{قسم الأذن والأنف و الحنجرة، كلية طب الأزهر}

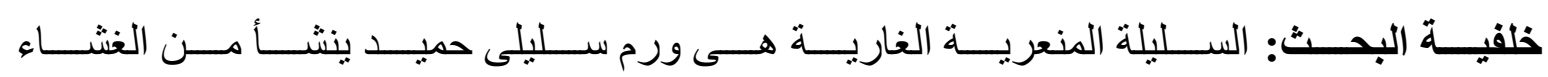

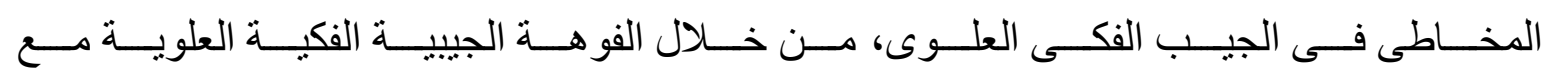

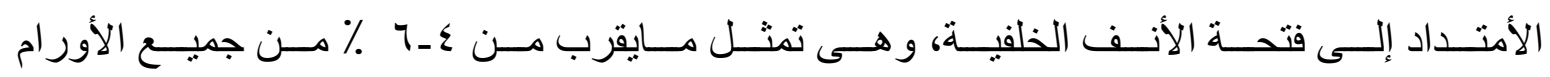

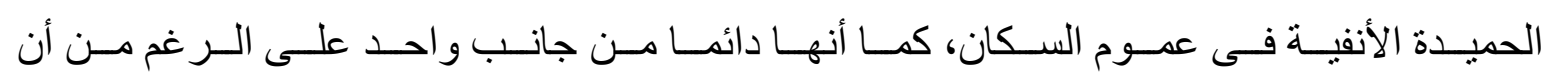
هناك حالات قليلة ثنائية الجنب.

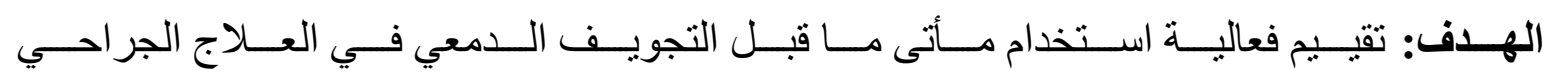

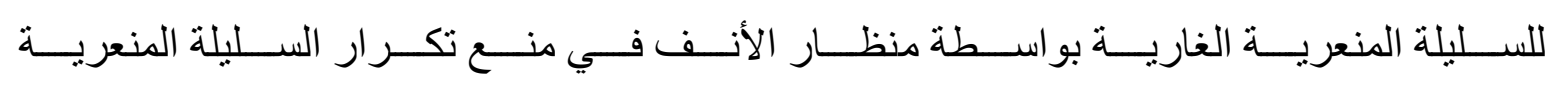

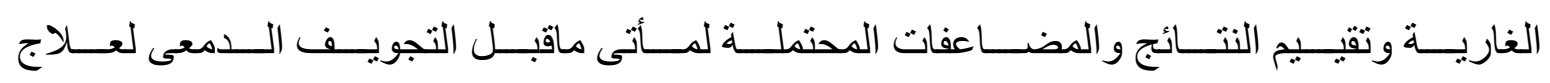
السليلة المنعرية الغارية.

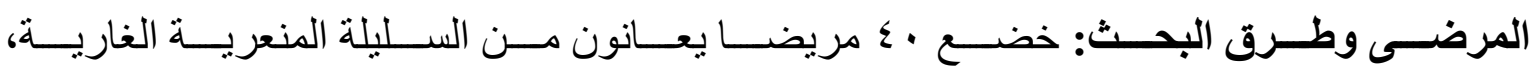

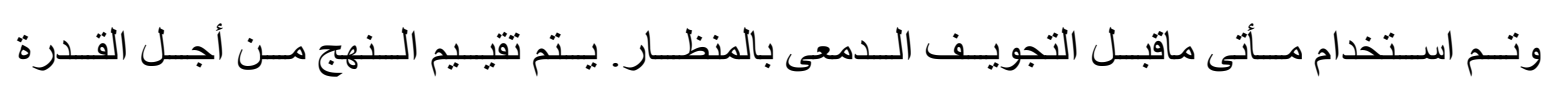
على تصور منشأ السليلة في تجويف الفك العلوي ، مضاعفات وتكر ار السليلة.

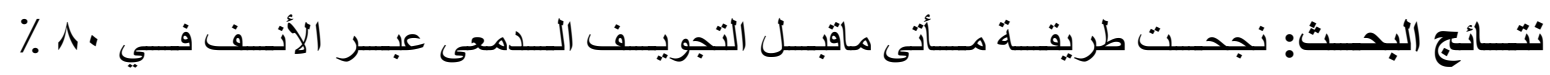

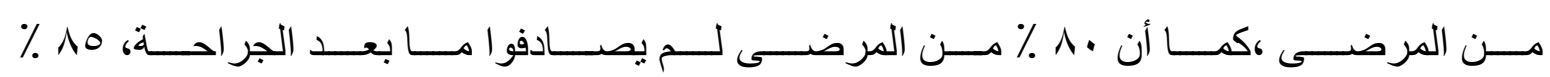

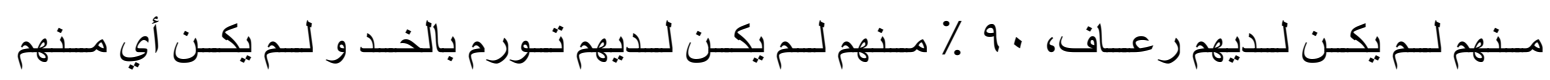

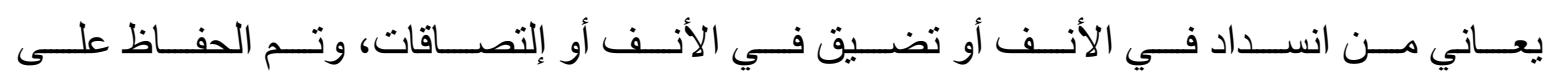

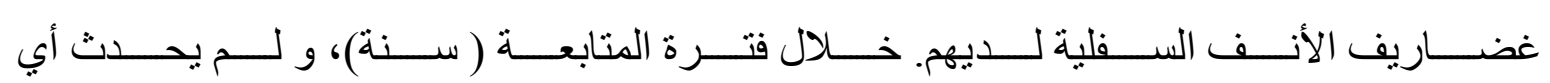
إرتجاع.

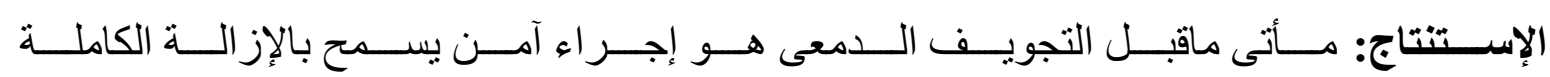
للجزء الغارى من السليلة المنعرية الغارية لمنع التكرار دون مضاعفات كبيرة. كلمات البحث: مأتى ماقبل التجويف الدمعى، السليلة المنعرية الغارية. 